\title{
Joint Range of Motion Decreased Cervical Spine, CTCAE
}

National Cancer Institute

\section{Source}

National Cancer Institute. Joint Range of Motion Decreased Cervical Spine, CT CAE. NCI

Thesaurus. Code C143627.

A disorder characterized by a decrease in flexibility of a cervical spine joint. 